\title{
O Facebook e o Smartphone: tecnologias que convergem para a aprendizagem da Química
}

\author{
Érica Raina Venâncio Almeida \\ Elisângela Soares Ribeiro
}

\section{Resumo}

Este trabalho objetiva apresentar uma experiência de sala de aula, utilizando das Tecnologias Digitais da Informação e Comunicação (TDIC) para o aprendizado no componente curricular "Química Geral e Experimental II”, com carga horária de 30 horas, em uma Universidade Estadual no interior da Bahia, no segundo semestre de 2014. Os conteúdos abordados de maneira presencial e online fora: Fatores que afetam a velocidade das reações químicas; Equilíbrio químico; Equilíbrio em solução aquosa; e, Eletroquímica. Em ambos utilizamos das potencialidades da rede social (Facebook) como proposta pedagógica de mediação da aprendizagem em Química; e dos recursos do Smartphone para produzir vídeos de experimentos, tirar fotos para anexá-las ao relatório, uso da internet para acessar artigos para estudo complementar dos conteúdos, e o cronômetro para registrar o tempo de término das reações químicas. Concluímos que as TDIC têm assumido um papel importante no ambiente acadêmico e que com planejamento sistematizado, objetivos de aula delimitados, e uso consciente, elas podem ser recursos que complementam e enriquecem as práticas educacionais em Química, além de ser uma excelente alternativa para o desenvolvimento do processo de ensino e de aprendizagem, independente da área do conhecimento.

Palavras chave: Aprendizagem da Química. Facebook. Smartphone. 


\section{Introdução}

A comunicação é algo necessário e presente na vida do ser humano. Com o passar dos anos e com a rapidez com que as Tecnologias Digitais da Informação e Comunicação (TDIC) foram sendo geradas, surgiu a necessidade do homem aperfeiçoar suas maneiras de uso, a fim de facilitar a disseminação do conhecimento pelo ato da comunicação e da informação. Ao utilizar sua capacidade racional, o ser humano passa a criar inúmeras tecnologias, em especial, as digitais, com o intuito de satisfazer as necessidades de adaptação de várias ações à era moderna, passando, assim, a criar novos meios de relacionamentos, de pesquisas, e ampliar as reflexões nos processos que envolvem a educação.

Lidar com as tecnologias advindas do século XXI requer novos hábitos para a geração do conhecimento. Requer também novas maneiras de conceber as informações, o armazenamento e a disseminação pelos espaços acadêmicos. "Neste cenário, pode-se dizer que o maior desafio dos professores na sociedade atual é apreender seu novo papel e compreender as TIC e o lugar delas no processo de ensino e aprendizagem" (ROSA; CECÍlIO, 2010, p.110).

Assim, é indicado que aos usuários do espaço educacional, sejam eles professores, pesquisadores, ou estudantes, possuam consciência crítica do uso das tecnologias, utilizandoas para melhorar a qualidade do ensino e da aprendizagem, da formação do professor, seja ela inicial ou continuada, e também das pesquisas realizadas que, por muitas vezes, dependem deste cenário.

Tendo em vista que as tecnologias digitais permeiam grande parte do contexto de vivência do homem, o objetivo deste trabalho é apresentar experiências ocorridas em sala de aula, com o uso das tecnologias digitais. Utilizamos da rede social (Facebook) e do Smartphone, para o desenvolvimento do componente curricular "Química Geral e Experimental II" de carga horária 30 horas, que envolveram os conteúdos: Fatores que afetam a velocidade das reações químicas; Equilíbrio químico; Equilíbrio em solução aquosa; e, Eletroquímica, do Curso de Bacharelado em Química em uma Universidade Estadual no interior da Bahia, no segundo semestre de 2014.

As atividades foram desenvolvidas presencial e online. Na primeira, etapa foram apresentados os conteúdos pelo professor com a metodologia expositiva e demonstrativa na sala de aula e no Laboratório de Química; e na segunda, foram disponibilizados espaços de discussões como um grupo fechado no Facebook ao qual foi disponibilizado um Fórum de Discussão, listas de exercícios e textos com a finalidade de complementar a aprendizagem dos conteúdos. Neste espaço também, foram postadas as fotos e os vídeos das reações químicas, assim como, os relatórios das aulas. 


\section{Funcionalidades do Smartphone como recurso pedagógico}

Já não vivemos mais isolados, nos conectamos com uma, duas, três ou mais tecnologias. Neste processo de interligação da construção entre o viver pessoal e profissional, deparamos com experiências que nos proporcionam novas possibilidades de aprender. Quando tratamos do contexto educacional no espaço cibernético ${ }^{1}$, os conhecimentos e os saberes podem estar direcionados para o saber lidar com as limitações, as potencialidades, as possibilidades, e a adequação dos recursos tecnológicos (computadores, softwares, celulares, etc.) no que se refere aos conteúdos e as práticas pedagógicas.

Saber lidar com estas tecnologias é a fase inicial para que uma pessoa consiga utilizar com o propósito de ensinar determinado conteúdo. Em seguida, há uma necessidade de entender que suas potencialidades se modificam quando são relacionadas didaticamente com os conteúdos, conduzindo a prática docente ao processo reflexivo e aos questionamentos. Isso permite ao professor realizar um estudo minucioso das funcionalidades dos recursos tecnológicos, uma vez que estes, possuem em sua estrutura intencionalidades, potencialidades, e objetivos, não podendo ser vistos como obstáculos para a realização de propostas pedagógicas para o ensino e a aprendizagem. Sobre estes aspectos Purificação, Neves e Brito (2010) destacam que

[...] com a chegada dos computadores, à escola, sentimentos contraditórios se apresentam claramente, como: ansiedade, insegurança, alegria, incompreensão, curiosidade, desorientação, ânimo, entre outros. Observa-se a sedução pelo novo, por uma ferramenta que pode trazer mudanças em suas ações didáticas, [...]. Com a sedução, vem ao mesmo tempo o medo do fracasso perante o novo, face à responsabilidade do erro, não o erro do aluno, mas do professor, e, consequentemente, a descoberta da necessidade de se aprimorar o uso do computador nas escolas. (PURIFICAÇÃO; NEVES; BRITO, 2010, p. 42).

Na discussão desses autores, é compreensível que só se aprende sobre uma tecnologia, utilizando-a, não importa se a pessoa é um professor ou um universitário. Como estudantes do segundo semestre do curso de Bacharelado em Química em uma Universidade no interior da Bahia, recebemos a proposta de um professor para utilizar das TDIC como suporte e recurso de estudo, de realização de pesquisas, de relatórios, da produções e apresentações de seminários e, principalmente, como um meio de comunicação acadêmica exterior à sala de aula, com o propósito de realizar questionamentos, sanar dúvidas, e realizar discussões referente ao conteúdo ministrado na disciplina.

Nesta vivência é visível que as tecnologias funcionam como coadjuvantes na aquisição de habilidades cognitivas que contribuem para o desenvolvimento de métodos e

${ }^{1}$ É a instauração de uma rede de todas as memórias informatizadas e de todos os computadores. (LÉVY, 2000). 
práticas, facilitando a evolução e aperfeiçoamento do conhecimento em Química. Neste mesmo intuito as TDIC vêm, por meio das funções de hardwares e softwares, proporcionar o desenvolvimento da comunicação, dos processos de desenvolvimento de pesquisas científicas, e, principalmente, da relação entre a teoria e a prática, podendo facilitar o aprendizado em diversas áreas do conhecimento.

Em pleno século XXI, não se pode limitar o aprendizado educacional à teoria e à sala de aula. O acesso à internet abre possibilidades de redefinir os modelos de ensino tradicionais para uma abordagem inovadora focada nas potencialidades das mídias sociais. No contexto digital, a todo tempo,

[...] surgem novos tipos ou versões mais atualizadas de linguagens de programação, sistemas operacionais, softwares, aplicativos para internet, redes sociais e equipamentos eletrônicos multifuncionais portáteis, como notebooks, tablets, telefones celulares, câmeras digitais, dentro outros. (BORBA; SILVA; GADANIDIS, 2014, p.17).

A partir destes recursos que promovem a integração das TDIC na educação, pode se proporcionar um aprendizado diferenciado pela contextualização dos conteúdos teóricos desenvolvidos em sala de aula. Neste contexto, o professor quando se propõe utilizar alguma tecnologia como recurso pedagógico, precisa ter claro os objetivos de ensino para oferecer aos estudantes caminhos que conduzam a aquisição do conhecimento acadêmico.

"Essa nova forma de ensinar não é fácil para professores acostumados com seu papel tradicional de comunicar e transmitir o que ensinam e conhecem bem". (ROSA; CECÍLIO, 2010, p. 111). Requer, deste modo, pesquisa, investigação das necessidades de aprendizagens, planejamento adequado às potencialidades da tecnologia que irá utilizar como recurso pedagógico. Desta maneira, será mais fácil o aprendiz interagir e compreender os processos de aprendizagens ao qual estão sendo submetidos.

Nos experimentos em Química, professores e estudantes utilizavam as TDIC de diversas maneiras. Logo nas primeiras aulas foi visível que o uso de recursos tecnológicos torna prático aquilo que lemos nos livros, pois além de apresentar vídeos sobre o conteúdo, também era possível visualizar imagens tridimensionais de cadeias químicas, dos elementos químicos, e dos resultados de experimentos. Desta maneira, aproveitamos do Smartphone para produzir vídeos dos experimentos realizados nas aulas presenciais, tirar fotos para anexá-las ao relatório e o cronômetro para contar o tempo que a reação levou para atingir ao seu processo final.

Mattar (2013) ao inferir sobre a utilização de celulares na educação, aponta que é um forte aliado no desenvolvimento da aprendizagem do estudante. Quando este lança mão do aparelho celular há possibilidades de acesso aos conteúdos em qualquer lugar e hora, sem 
necessariamente estar no contexto físico da sala ade aula. A UNESCO quando constrói as diretrizes de políticas para a aprendizagem móvel, traz considerações sobre o uso de celulares na educação e também afirma que possuem "[...] mais de 3,2 bilhões de assinantes de telefonia celular em todo o mundo, tornando o telefone celular a TIC interativa mais amplamente usada no planeta”. (UNESCO, 2014, p. 9). Este fato remete a reflexão de que as escolas e universidades estão recheadas de estudantes que fazem uso desta tecnologia, e que a mesma pode ser utilizada como recurso pedagógico e facilitador do ensino e da aprendizagem em qualquer área do conhecimento.

Borba, Silva e Gadanidis (2014, p.77) também relatam que "Os usos dessas tecnologias já moldam a sala de aula, criando novas dinâmicas, e transformando a inteligência coletiva, as relações de poder, [...] e as normas a serem seguidas nessa mesma sala de aula”. A aprendizagem em Química, desta maneira, deixa de ser centralizadora na figura do professor e passa a ser disseminada, acessada por qualquer pessoa que possua um aparelho de celular conectado à rede de internet.

A utilidade de um smartphone além de ser conectado as redes sociais, a exemplo do Facebook, também pode possibilitar a convergência de mídias.

Por convergência, refiro-me ao fluxo de conteúdos através de múltiplas plataformas de mídia, à cooperação entre múltiplos mercados midiáticos e ao comportamento migratório dos públicos dos meios de comunicação, que vão a quase qualquer parte em busca das experiências de entretenimento que desejam. Convergência é uma palavra que consegue definir transformações tecnológicas, mercadológicas, culturais e sociais, dependendo de quem está falando e do que imaginam estar falando. (JENKINS, 2008, p. 29).

Aqui compreendemos que a convergência midiática não acorre somente na junção de diversas funções em apenas um aparelho, mas as interlocuções, os diálogos, as construções de saberes, nos compartilhamentos de objetos e ideias. No tocante a experiência em questão, citamos a agregação de funções do computador ao celular, do uso da câmera digital, e do cronômetro, das discussões do grupo fechado no Facebook, que tanto envolviam pessoas, quanto o celular, a rede social, e os saberes adquiridos. Ramal (2011) conjectura que para interferir nos processos de aprendizagens, "As tecnologias intelectuais da pósmodernidade - com seus suportes hipertextuais, interconectados e interativos - questionam a escola e sua fragmentação disciplinar, suas grades curriculares tão pouco propícias ao diálogo entre os saberes”. (RAMAL, 2011, p.188).

Estas características inerentes das tecnologias digitais que se apresenta sem linearidade, e pelo modelo hipertextual, possibilita aos estudantes adquirir a liberdade de estudar em qualquer lugar, não tendo a obrigação de estar em frente a um computador para desenvolver as atividades educativas. As instituições educacionais, por sua vez, têm adquirido ISSN 2526-2882 
muitas posturas que dão abertura aos momentos de aprendizagens acadêmicas, e ao longo dos tempos vem reconfigurando propostas educacionais que colocam em evidência a movimentação social do uso de diversas tecnologias. Isso se dá, ao perceber que:

O re-uso e a reconfiguração que ocorre com os aplicativos da rede compõem uma dinâmica que está contaminando as telecomunicações digitais, ou seja, as práticas colaborativas, presentes na internet, estão atingindo o mundo da infra-estrutura, gerando novas possibilidades de comunicação, além de ampliar o acesso às redes e à diversidade de produção cultural. (SILVEIRA, 2008, p.42).

Percebe-se que utilizar as TDIC na educação é uma proposta inovadora que facilita a aproximação do conhecimento científico para os acadêmicos, incutindo neles possibilidades diversas de alcançar novos aprendizados, novas metodologias, novos caminhos de adquirir e disseminar os saberes da Química ao longo do processo de formação profissional. Esta postura requer dos atores envolvidos a compreensão de que o uso consciente e objetivado das TDIC acarretará em benefícios de aprendizagem que resultam no crescimento cognitivo, na formação profissional e pessoal, na construção de saberes, e no compartilhamento de experiências.

\section{As potencialidades do Facebook na aprendizagem da Química}

$\mathrm{Na}$ era da informação, a educação requer uma configuração mais próxima da realidade dos atores que em seu contexto social, dialogam, trocam informações, sugestionam, refletem, se posicionam, etc. Os professores, neste contexto não são detentores do saber, mas interlocutores, orientadores, compartilhadores de conhecimentos.

Na tentativa contínua de não reproduzir velhos esquemas de aulas, utilizamos de outro recurso digital que foi a rede social Facebook, para a continuidade da aprendizagem do componente curricular "Química Geral e Experimental II".

Pode se dizer que o Facebook é um ambiente virtual e definido por Santos (2011, p. 225) como "[...] um espaço fecundo de significados onde os seres humanos e objetos técnicos interagem, potencializando assim a construção do conhecimento, logo a aprendizagem”. Sendo assim, compreendemos que não somente nos momentos de descontração social ocorre a interação, mas dentro dos muros das Universidades, as TDIC têm conquistado espaço e desempenhado um papel importantíssimo para o ato de formação pessoal e profissional do cidadão. Contudo, é possível perceber que:

Cada vez mais o tempo que os estudantes têm de aula presencial em cada disciplina é menor, e os objetivos e conteúdos a serem cumpridos em determinado período de tempo, são enormes. [...] Se faz necessário explorar 
novos espaços de aprendizagem além dos muros da escola, e ainda descobrir recursos que mobilizem o aprender a aprender dos estudantes nestes diversos espaços de aprendizagem, [...]. (BONA; FAGUNDES; BASSO, 2012, p.3-4).

No entanto, compreendemos que é possível e coerente que em pleno século XXI, professores em todos os níveis educacionais passem a explorar as potencialidades das tecnologias, como fator motivador, para ajudar na compreensão de alguns conteúdos tidos como difíceis de serem compreendidos. No caso de universitários, essa proposta pode ajudar na sustentação do caminhar acadêmico, deixando-o mais prazeroso e sem maiores dificuldades em prosseguir neste universo que é o da formação profissional na área da Química.

Desta forma, em continuação do relato da experiência, pretendemos demonstrar como as TDIC tem, por meio das redes sociais, ajudado a complementar o aprendizado desta área do conhecimento dentro e fora da sala de aula.

Tomando como premissa de que o Facebook é um aliado no processo de aprendizagem, esta plataforma "[...] permite que, além de textos escritos, imagens, vídeos sejam incorporados ao fórum, oferecendo um caráter multimodal ao cenário de interação”. (BORBA; SILVA; GADANIDIS, 2014, p.84). Os vídeos apresentam um recurso importante na educação, através dele é possível associar imagens, aos sons, ao movimento, a escrita, sendo um rico produto para acesso de informações. Utilização de vídeos, de acordo com Bates (2012 apud Mattar, 2013), ainda é subutilizado em educação, muitas vezes são como um extra ou uma reflexão tardia, em vez de ser parte integrante da aula. Por outro lado, com o avanço da configuração do World Wide Web (WWW), há maior contato dos usuários com os recursos midiáticos, possibilitando que os softwares, por exemplo, nunca estejam prontos, mas em contínuo aperfeiçoamento, permitindo a implementação de outros recursos em curto intervalo de tempo.

Na experiência em evidência, a estrutura do Facebook permitiu de diversas maneiras a facilidade de interação, cooperação, comunicação e colaboração. As potencialidades das interfaces incorporadas nesta tecnologia podem ajudar, de forma significativa, o desenrolar do processo de ensino e de aprendizagem, desde que haja um planejamento rigoroso voltado para os fins educacionais. Para Mattar (2013, p.30), utilizar redes sociais para ensinar "[...] implica, de uma maneira geral, mudanças de teorias pedagógicas centradas no professor para teorias mais participativas, colaborativas, sociais e centradas no aluno".

$\mathrm{Na}$ referida rede social existem certos espaços que foram explorados na aprendizagem da Química. Como exemplo citamos o uso do recurso "Eventos", onde sua utilização serviu para alertar sobre os conteúdos primordiais para o processo de formação, além de servir para agregar pessoas com interesses comuns sobre os conteúdos abordados ISSN 2526-2882

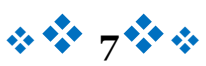


pelo professor, fator que trouxe contribuições que favoreceram o crescimento cognitivo dos discentes.

Outro espaço potencialmente rico foi o "Mural" utilizado para postagens e publicações (dúvidas, lista de exercícios complementares, anúncios, recados, relatórios). Este espaço tornou-se um local apropriado para disseminar a comunicação entre o professor e os estudantes, pois por se tratar de um espaço público, podia ser acessado e visualizado pelos discentes. Neste sentido, “[...] as relações entre alunos e professores construídas no Facebook podem gerar um canal de comunicação mais aberto, resultando em ambientes de aprendizagens mais ricos e maior envolvimento dos alunos”. (MATTAR, 2013, p. 115).

A ferramenta eventos foi utilizada para anunciar o calendário de atividades da disciplina, como as datas das provas, e reuniões importantes. Um chat foi criado pelo professor da disciplina, formando um grupo de conversas, contendo todos os alunos de sua disciplina. Este espaço virtual nos proporcionou a comunicação em tempo real, sendo de grande utilidade, principalmente para a comunicação do compartilhamento dos resultados das experiências ocorridas na sala de aula. Tivemos, ainda, a oportunidade de aumentar a comunicação com o professor, tirar as dúvidas dos conteúdos propostos na sala de aula, além de trocarmos informações diversas sobre a Química.

Por este contexto, utilizar o Facebook como uma tecnologia digital e alternativa na educação proporciona maior interação entre discentes e docentes, até mesmo entre estudantes e conteúdos. O uso desses meios de comunicação, é também, uma forma dinâmica de ensinar e de aprender. Neste sentido, utilizar as TDIC a favor da educação, faz com que a aquisição dos conhecimentos científicos se torne algo mais dinâmico e prazeroso, diversificado, e para alguns, mais interessante e instigante do que apenas as aulas que se limitam aos espaços territoriais impostos pela sala de aula tradicional.

No mundo globalizado em que vivemos, e na era da informação veloz a que estamos submetidos, a presença de tecnologias digitais está cada vez mais presente na situação social vigente. Este contexto demonstra que:

Somos convocados a repensar a relação educação-trabalho, no âmbito da sociedade globalizada, à luz das Tecnologias de Informação e Comunicação que apontam para um saber fazer social diferenciado exigindo da escola reflexão e a produção de outras habilidades, capacidades mentais, cognitivas e afetivas [...]. (TORRES, 2012, p.52).

Para que os atores educacionais vivenciem o que descreve Torres (2012), muitas políticas de inclusão social precisam ser criadas para garantir a potencializar da comunicação em rede, e também ser suficiente para que todos possam alcançar. Não é demagogia que as TDIC têm contribuído para que o homem, em praticamente todos os ramos de suas vidas, e 
agora ainda mais na área educacional, atinja seus objetivos para a realização de projetos pessoais.

No que diz respeito ao ensino e aprendizagem da Química, onde possuem uma gama de conteúdos considerados complexos, o suporte oferecido pelas tecnologias, em muitos casos, tem propiciado: ajuda na resolução de problemas; rapidez de informações; instantaneidade nas comunicações, seja por mensagens de celular ou por redes sociais; dinamismo e novas oportunidades de interação, comunicação e relacionamentos.

Sendo assim, utilizar o Facebook permitiu que o professor e os estudantes tivessem acesso as vantagens de uma comunicação mais aberta e informal, resultando em um ambiente de aprendizagem rico e satisfatório. Isso foi possível pela elaboração do planejamento de aula do professor e também da familiaridade em que os acadêmicos possuíam em utilizar a rede social no cotidiano. Nestes aspectos, passaram a explorar as potencialidades desta interface e tirar proveito para o desenvolvimento educacional. Essa facilidade é discutida por aurores que defendem que:

[...] inserir mídias sociais, no caso o Facebook, no contexto estudantil tornase uma tarefa fácil, já que os nativos digitais já estão habituados a utilizar as mídias digitais assiduamente. $\mathrm{O}$ uso de tal plataforma como articuladora da rede educacional ultrapassaria as distâncias, aumentando a interação entre alunos e professores. (ALENCAR; MOURA; BITENCOURT, 2013, p.91).

O acesso ao Facebook na atualidade tem sido um dos principais meios para adquirir às informações e fomentar a socialização. O uso tem se tornado rotina nas ações de grande parte das pessoas, onde desenvolvem tarefas seja na modalidade individual ou coletiva, impulsionando muitas pessoas a conectar-se e buscar usá-las agregadas a outros meios de comunicação. Diante de todas estas vantagens, fica o questionamento: Por que não utilizar as tecnologias digitais para beneficiar e enriquecer o processo educacional? Certamente esta metodologia pode ser benéfica para a realização de inúmeras atividades, além das apresentadas aqui.

\section{Considerações}

No relato, apresentamos as diversas vantagens educacionais proporcionadas pelas potencialidades da rede social (Facebook) e do uso do Smartphone. Os usos só foram possíveis pela abertura da rede de internet, que coloca em evidência a utilização foram dos espaços territoriais pré-estabelecidos, no caso da educação, a sala de aula. Elas, ainda, promoveram o aumento da comunicação e a possibilidade de interação entre os conteúdos educacionais e seus usuários. 
É coerente afirmar que os usuários da internet, neste século XXI, são, além de detentores e disseminadores das informações, construtores de seus próprios ritmos de aprendizagens. Nesta ótica, consideramos que o Facebook e o Smartphone são processos tecnológicos que convergiram para o desenvolvimento do aprendizado científico em Química. Isso só foi possível porque o professor, engajado com qualidade da educação prestada, elaborou o planejamento de aula com os objetivos voltados para as potencialidades das tecnologias, identificando previamente como elas poderiam ser utilizadas para facilitar a aprendizagem em Química dos discentes.

Por meio das experiências relatadas, é possível defender que as Tecnologias Digitais da Informação e Comunicação têm ganhado espaço no ambiente acadêmico e se tornado peça importante nos processos de ensinar e aprender. Entendemos que estes processos são criados a partir do entrelaçamento de diálogos e das trocas de experiências, que são potencializados e mediados pelo uso das TDIC.

Detalhadamente, compreendemos que a rede social (Facebook), facilitou a construção do aprendizado individual e coletivo, promoveu a integração entre professor e estudantes, possibilitou o compartilhamento e ampliação do conhecimento para além da sala de aula, foi espaço de discussões de conteúdos acadêmicos e de retirada de dúvidas sobre a Química. Os internautas/estudantes, neste sentido, deixaram de ser apenas consumidores passivos das informações, passando a interagir, cooperar, colaborar, compartilhar informações e saberes, expressando suas opiniões e sentimentos de maneira livre e também articulada. O Smartphone, por sua vez, contribuiu na medida em que apresentou recursos que facilitou a construção e disseminação das atividades desenvolvidas nas aulas presenciais, ofereceu recursos para delimitar o tempo das reações, e serviu para registrar momentos de aprendizagens e descobertas do conhecimento acadêmico.

Assim, acreditamos que, com planejamento sistematizado, objetivos de aula delimitados, e uso consciente, as TDIC podem ser recursos que complementam e enriquecem as práticas educacionais em Química, além de ser uma excelente alternativa para o desenvolvimento do processo de ensino e de aprendizagem, independente da área do conhecimento.

\section{Referências}

ALENCAR, G. A; MOURA, M. R; BITENCOURT, R. B. Facebook como Plataforma de Ensino/Aprendizagem: o que dizem os Professores e Alunos do IFSertão - PE. Revista Educação, Formação \& Tecnologias. Recife, v. 6, n.1, p. 86-93, julho, 2013.

ISSN 2526-2882

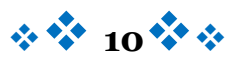


BATES, T. Pedagogical roles for vídeo in online lerrning. Online Learning and Distabce Education Resources, 10 mar. 2012 apud MATTAR, J. Web 2.o e redes sociais. São Paulo: Artesanato Educacional, 2013.

BONA, A. S; FAGUNDES, L. C; BASSO, M. V. A. Facebook: um possível espaço digital de aprendizagem cooperativa da Matemática. Revista Novas Tecnologias na Educação. CINTED-UFRGS. v. 10, n. 3, Dezembro, 2012.

BORBA, M. C; SILVA, R. S. R; GADANIDIS, George. Fases das tecnologias digitais em Educação Matemática: sala de aula e internet em movimento. 1. Ed. Belo Horizonte: Autêntica Editora, 2014.

JENKINS, H. Cultura da Convergência. São Paulo: Aleph, 2008.

LÉVY, P. A emergência do Cyberspace e as mutações culturais. In: PELLANDA, N. M. C; PELlandA, E. C. (Orgs.). Ciberespaço: um hipertexto com Pierre Lévy. Porto Alegre: Artes e Ofícios, 2000.

MATTAR, J. Web 2.o e redes sociais. São Paulo: Artesanato Educacional, 2013.

PURIFICAÇÃO, I; NEVES, T. G; BRITO, G. S. Professores de Matemática e as tecnologias: medo e sedução. In: BELINE, W; COSTA, N. M. L. (org.). Educação Matemática, tecnologia e formação de professores: algumas reflexões. Campo Mourão: Editora da FECILCAM, 2010.

RAMAL, A. C. Educação com tecnologias digitais: uma revolução epistemológica em mãos do desenho instrucional. In: SILVA, M. (org.). Educação online: teorias, práticas, legislação, formação corporativa. 3. Ed. São Paulo: Editora Loyola, 2011.

ROSA, R; CECÍlLIO, S. Educação e o uso pedagógico das Tecnologias da Informação e Comunicação: a produção do conhecimento em análise. Revista Educ. foco. Juiz de Fora, v. 15, n. 1, p. 107-126, mar 2010/ago 2010.

SANTOS, E. Articulação de saberes da EAD online: por uma rede interdisciplinar e interativa de conhecimentos em ambientes virtuais de aprendizagem. In: SILVA, M. (org.). Educação online: teorias, práticas, legislação, formação corporativa. 3. Ed. São Paulo: Editora Loyola, 2011.

SILVEIRA, S. A. Convergência digital, diversidade cultural e esfera pública. In: PRETTO, Nelson De Luca; SILVEIRA, Sérgio Amadeu da (Org). Além das redes de colaboração: internet, diversidade cultural e tecnologias do poder. Salvador: EDUFBA, 2008.

TORRES, M. M. O. Formação docente em pauta: as tecnologias nos contextos formativos. Salvador: EDUNEB, 2012.

UNESCO. Organização das Nações Unidas para a Educação, a Ciência e a Cultura (UNESCO).

Diretrizes de políticas para a aprendizagem móvel. Disponível em: ISSN 2526-2882 
<http://unesdoc.unesco.org/images/o022/o02277/227770por.pdf>. Acesso em: 23 de Outubro, 2018.

\section{Biografia Resumida}

Érica Raina Venâncio Almeida: Graduanda em Química pela Universidade Estadual do Sudoeste da Bahia - UESB, campusJequié - BA.

e-mail: erica.venancioo1@hotmail.com

Elisângela Soares Ribeiro: Mestre pelo Programa de PósGraduação em Educação Científica e Formação de Professores da Universidade Estadual do Sudoeste da Bahia - UESB, campus- Jequié - BA.

e-mail: elysangelaribeiro@gmail.com 